in the presence of sodium hydroxide. The reaction is not quantitative; some ammonia is also formed.

Nitrogen trichloride reacts slowly with dilute ammonium chloride solution and more rapidly with a concentrated solution to give nitrogen and hydrochloric acid.

Berkeley, California.

[CONTRIBUTION FROM THE CHEMTCAI, LABORATORY OF THE UNIVERSITY OF CALIFORNia.]

\title{
THE REACTIONS BETWEEN CHLORINE AND AMMONIA.
}

By WIILIAM C. BRAY AND C. T. DOWELL.

Received March 10, 1917.

The reactions between chlorine and ammonia in aqueous solution furnish striking examples of changes in the nature of the products which result from variations in the experimental conditions.

I. Nitrogen trichloride is formed very rapidly and almost quantitatively in the following reactions when excess of a strong acid is present: ${ }^{1}$

$$
\begin{gathered}
\mathrm{NH}_{3}+{ }_{3} \mathrm{Cl}_{2}=\mathrm{NCl}_{3}+3 \mathrm{H}^{+}+{ }_{3} \mathrm{Cl}^{-} \\
\mathrm{NH}_{4}^{+}+{ }_{3} \mathrm{Cl}_{2}=\mathrm{NCl}_{3}+{ }_{4} \mathrm{H}^{+}+{ }_{3} \mathrm{Cl}^{-} \\
\mathrm{NH}_{4}+\mathrm{Cl}^{-}+{ }_{3} \mathrm{HClO}^{-} \mathrm{NCl}_{3}+\mathrm{H}^{+}+\mathrm{Cl}^{-}+{ }_{3} \mathrm{H}_{2} \mathrm{O}
\end{gathered}
$$

The first two reactions are evidently closely related, and the third one is to be regarded as practically identical with the second on account of the rapid hydrolysis equilibrium for chlorine: $\mathrm{Cl}_{2}+\mathrm{H}_{2} \mathrm{O}=\mathrm{HClO}+$ $\mathrm{H}^{+}+\mathrm{Cl}^{-}$. Thus in the experiments with hypochlorous acid and ammonium chloride chlorine would form unless the reaction between $\mathrm{HClO}$ and $\mathrm{NH}_{4}{ }^{+}$is faster than the reaction between $\mathrm{HClO}$ and $\mathrm{HCl}$. Similarly in the experiments with chlorine hypochlorous acid will form unless the chlorine reacts with $\mathrm{NH}_{4}{ }^{+}$faster than it can react with water. ${ }^{2}$ In the final solution, which contains $\mathrm{NH}_{4}+, \mathrm{H}^{+}$and $\mathrm{Cl}^{-}$, there is a slow followreaction, $\mathrm{NCl}_{3}+\mathrm{NH}_{4}+=\mathrm{N}_{2}+{ }_{4} \mathrm{H}^{+}+{ }_{3} \mathrm{Cl}^{-}$, which has been discussed in the final section of the preceding article. Its speed increases with the concentration of the ammonium chloride and with the temperature.

2. When excess of a base is present nitrogen gas is evolved rapidly and almost quantitatively in the following reactions:

$$
\begin{gathered}
2 \mathrm{NH}_{3}+3 \mathrm{Cl}_{2}=\mathrm{N}_{2}+6 \mathrm{H}^{+}+6 \mathrm{Cl}^{-} \\
8 \mathrm{NH}_{3}+{ }_{3} \mathrm{Cl}_{2}=\mathrm{N}_{2}+6 \mathrm{NH}_{4}++6 \mathrm{Cl}^{-} \\
2 \mathrm{NH}_{3}+{ }_{3} \mathrm{ClO}^{-}=\mathrm{N}_{2}+{ }_{3} \mathrm{Cl}^{-}+3 \mathrm{H}_{2} \mathrm{O}
\end{gathered}
$$

1 For references see the first section of the preceding article.

${ }^{2}$ For a number of reactions of the halogens in aqueous solution there is evidence that the primary reaction is the hydrolysis of the halogen and that the hypohalous acid is a more reactive sustance than the halogen. See Bray, Z. physik. Chem., 54, 463, 497 (1906). However, these reactions involve the addition of oxygen, $e$. g., the oxidation of arsenious acid by iodine, and the theory was not intended to apply to substitution reactions. In the present instance we have no means of deciding whether $\mathrm{Cl}_{2}$ or $\mathrm{HClO}$ is the more reactive substance. 
The first two equations represent the same reaction except that the neutralization of the acid by the excess ammonia is shown in the second equation. This reaction is the basis of the Hofmann lecture experiment ${ }^{1}$ which serves to demonstrate that the volume of the nitrogen formed is one-third that of the chlorine gas used. This result, however, is obtained only when an excess of concentrated ammonium hydroxide is present, and time is allowed for the last portion of the nitrogen gas to be formed; otherwise too small a volume of nitrogen is liberated. Reaction $2 c$ was used for a while as a quantitative method for the determination of ammonia, but hypobromite ${ }^{2}$ is now used instead of hypochlorite, because with the latter substance the evolution of nitrogen may not be complete. We tried a few preliminary experiments with the hypochlorite method, and found that after the rapid evolution of nitrogen bubbles of this gas continued to form slowly, and that a small quantity of an oxidizing agent (presumably $\mathrm{NH}_{2} \mathrm{Cl}$ ) remained in the solution for some time There is a possibility that the rapid and the slow evolution of nitrogen are two independent reactions (i.e., the main reaction and a side reaction); but it seems more reasonable to assume, for the present at least, that the evolution of nitrogen is not an extremely rapid reaction, and becomes slow when the concentration of either $\mathrm{NH}_{3}$ or $\mathrm{ClO}^{-}$is small.

3. According to Raschig 3 chloramine, $\mathrm{NH}_{2} \mathrm{Cl}$, is formed in solution very rapidly and almost quantitatively when dilute solutions of ammonia and sodium hypochlorite are mixed in equimolal quantities at low temperature.

$$
\mathrm{NH}_{8}+\mathrm{ClO}^{-}=\mathrm{NH}_{2} \mathrm{Cl}+\mathrm{OH}^{-} \text {. }
$$

This substance decomposes according to the equation

$$
3 \mathrm{NH}_{2} \mathrm{Cl}=\mathrm{N}_{2}+\mathrm{NH}_{3}+{ }_{3} \mathrm{H}^{+}+{ }_{3} \mathrm{Cl}^{-}
$$

and this reaction is rapid when the concentration of $\mathrm{NH}_{2} \mathrm{Cl}$ is large, when the temperature is high, or when the concentration of hydroxide ion or of ammonia is large. The sum of reactions $3^{a}$ and $3^{b}$ is Reaction $2 c$.

4. When chlorine gas was treated with $0.5 \% \mathrm{NH}_{3}$ solution in the proportion of $\mathrm{I} \mathrm{mol} \mathrm{Cl}_{2}$ to $\mathrm{I} .90^{\circ}-\mathrm{I} .95 \mathrm{mols} \mathrm{NH}_{3}$ Noyes and Lyon found that $\mathrm{N}_{2}$ and $\mathrm{NCl}_{3}$ were formed in equimolal quantities,

$$
\begin{gathered}
3 \mathrm{NH}_{3}+6 \mathrm{Cl}_{2}=\mathrm{N}_{2}+\mathrm{NCl}_{3}+9 \mathrm{H}^{+}+9 \mathrm{Cl}^{-} . \\
\text {I2 } \mathrm{NH}_{3}+6 \mathrm{Cl}_{2}=\mathrm{N}_{2}+\mathrm{NCl}_{3}+9 \mathrm{NH}_{4}+{ }_{9} \mathrm{Cl}^{-} .
\end{gathered}
$$

${ }^{1}$ Hofmann, Ber., I5, 2664 (1882).

2 Knop method, Classen, "Ausgewählte Methoden der Analyt. Chem.," Vol. II, 498 (I903); Fresenius, "Quant. Analysis," Translation by Cohn of 6th German ed., Vol, II, 885 (1904).

3 Raschig, Chem. Ztg., 31, 926 (I907).

- In the reaction between $\mathrm{NH}_{2} \mathrm{Cl}$ and ammonia some bydrazine was formed.

${ }^{5}$ Noyes and Lyon, THIS JOURNAL, 23, 460 (1901). 
The two equations represent the same reaction. The first equation is the simplest one that will show the formation of $\mathrm{N}_{2}$ and $\mathrm{NCl}_{3}$ in a single reaction; the second shows the neutralization of the acid by ammonia. According to the latter equation 2 mols $\mathrm{NH}_{3}$ to $\mathrm{I}$ of $\mathrm{Cl}_{2}$ are required to give a neutral solution, and since a somewhat smaller amount of $\mathrm{NH}_{3}$ was used by Noyes and Lyon the final solution was slightly acid. The volume of the nitrogen evolved is one-sixth the volume of the chlorine used. Noyes and Lyon considered this to be a true stoichiometric reaction and emphasized the improbability that such a reaction would take place if the liberation of $\mathrm{N}_{2}$ and the formation of $\mathrm{NCl}_{3}$ were independent reactions. They drew the additional conclusion that 6 molecules of chlorine must react simultaneously with 3 molecules of ammonia. However this conclusion that Reaction $4 a$ is the primary reaction between $\mathrm{Cl}_{2}$ and $\mathrm{NH}_{3}$ is open to criticism. A ninth order reaction is extremely improbable and an explanation based on intermediate reactions seems much more reasonable. In fact this reaction would be an example of "stoichiometric forking," which has been discussed by one of the authors, ${ }^{1}$ and could be used as a basis for a theory of the mechanism of the reaction between ammonia and chlorine. According to this view the $\mathrm{N}_{2}$ and $\mathrm{NCl}_{3}$ would have to be derived in equimolal quantities from a single intermediate substance or a single intermediate reaction. It is evident that the choice of intermediate reactions would be greatly limited by this restriction.

Such reasoning is based on the assumption that Reaction $4^{a}$ is a true stoichiometric reaction. The fact that this reaction takes place under a single set of experimental conditions, however, is not sufficient to justify this assumption. It is necessary to show that the ratio of $\mathrm{N}_{2}$ to $\mathrm{NCl}_{3}$ formed varies asymptotically from unity as the experimental conditions are gradually changed. Thus if for a series of experiments this ratio is plotted as ordinate and the factor which is varied is plotted as abscissa the curve obtained should show a point of inflection where the ratio is unity. On the other hand a steady change of this ratio would indicate that $\mathrm{N}_{2}$ and $\mathrm{NCl}_{3}$ are formed in independent reactions. A consideration of the available experimental evidence shows that the latter view is not unreasonable. As we have seen, the formation of $\mathrm{NCl}_{3}$ in acid solution is practically instantaneous and the evolution of $\mathrm{N}_{2}$ in alkaline solution is also a rapid reaction. It therefore is not surprising that some intermediate experimental condition should be found at which they are formed in equimolal quantities. Noyes and Lyon noted that it was necessary to observe carefully the given experimental conditions in order to obtain the normal reaction. When excess of concentrated ammonia was used, i. e., under the condition of the Hofmann experiment, they found that the

\footnotetext{
${ }^{2}$ Bray, Z. physik. Chem., 34, 465 (1906).
} 
volume of the nitrogen rapidly evolved approached one-third the volume of the chlorine but did not quite reach this limit. On the other hand when too little ammonia was used a larger proportion of $\mathrm{NCl}_{3}$ than that shown by the equation was formed. Furthermore it is to be noted that the nature of the solution changes greatly during such an experiment. When the first portion of the chlorine enters the solution excess of ammonia is present and the conditions are favorable for the formation of nitrogen, while at the end of the experiment or in any part of the solution where chlorine is present in excess, due to insufficient mixing, the solution is acid and the conditions are favorable for the formation of $\mathrm{NCl}_{3}$.

Experiments on the Reaction between Chlorine Gas and Ammonium Hydroxide Solution.

In order to obtain additional experimental evidence with regard to the reaction between chlorine gas and dilute ammonium hydroxide solution a number of experiments were performed. Experiments in which these substances were mixed in the proportion of $\mathrm{I} \mathrm{mol} \mathrm{Cl}_{2}$ to 2 mols $\mathrm{NH}_{3}$ were taken as a basis and the effect of the following factors was investigated: $(a)$ increase in the amount of ammonia used, (b) change of concentration of ammonium hydroxide solution, (c) decrease in temperature, $(d)$ the addition of the ammonium hydroxide solution in several portions instead of in one portion, and $(e)$ concentration of hydrogen ion during the reaction.

The chlorine gas was prepared and the experiments were performed with a graduated glass tube as described in the last section of the preceding article. A $0.496 \mathrm{~N}$ solution of ammonium hydroxide was used.

In the first experiments (with $\mathrm{I} \mathrm{mol} \mathrm{Cl}_{2}$ to $2 \mathrm{mols} \mathrm{NH}_{3}$ ) the volume of nitrogen liberated varied between 25 and $30 \%$ of the volume of chlorine used. This lack of reproducibility of the results was found to be due partly to a variation in the temperature but mainly to the fact that the time which was allowed to elapse before the volume of the nitrogen was measured was different in the different experiments. As has already been explained, nitrogen was evolved in a slow follow-reaction between $\mathrm{NCl}_{3}$ and the dilute solution of ammonium chloride. In all later experiments this error due to the follow-reaction was eliminated by measuring the volume of the nitrogen as soon as possible after the chlorine and ammonium hydroxide solution had been mixed. Fairly concordant results were then obtained and when the room temperature was about $32^{\circ} 38.8 \mathrm{cc}$. to $40.2 \mathrm{cc}$. nitrogen were obtained when the initial volume of the chlorine was $\mathrm{r} 43.6 \mathrm{cc}$., $i . e$., the volume of the nitrogen was 27.0 to $28.0 \%$ of that of the chlorine. The solution was faintly acid at the end of the experiment.

This ratio of the nitrogen and chlorine volumes is much greater than that found by Noyes and Lyon $(1 / 6$ or $16.7 \%)$ when a $2.5 \%$ to $5 \%$ smaller 
amount of ammonia was used. The difference is greater than can be accounted for by assuming that the extra ammonia which we used reacted with $\mathrm{NCl}_{3}$ to give nitrogen. It follows that the ratio of $\mathrm{N}_{2}$ to $\mathrm{NCl}_{3}$ increases rapidly as the ratio of $\mathrm{NH}_{3}$ to $\mathrm{Cl}_{2}$ is increased. This conclusion was supported by the results of a series of experiments in which gradually increasing volumes of the dilute ammonium hydroxide solution were used. This result is an indication that we are not dealing with a true stoichiometric reaction.

In the last experiments of this series when so much ammonium hydroxide had been added that the final solution was distinctly alkaline to litmus paper, the amount of nitrogen that was rapidly evolved was only slightly less than one-third the volume of the chlorine. Tests with potassium iodide showed that the solution contained a small amount of an oxidizing agent, possibly $\mathrm{NH}_{2} \mathrm{Cl}$. The amount of this oxidizing agent, and the alkalinity of the solution gradually decreased when the solution was allowed to stand 48 hours.

The effect of changing the concentration of the ammonium hydroxide without changing the actual amount introduced into the tube was determined. When the ammonium hydroxide solution was diluted twothree- and fourfold the volume of the nitrogen liberated at $32^{\circ}$ was between $27 \%$ and $28 \%$ the volume of the chlorine. The change in concentration thus had no effect. This result may be considered as evidence in favor of the validity of the Noyes and Lyon reaction; or it may mean that the chief factor in determining the ratio of $\mathrm{N}_{2}$ to $\mathrm{NCl}_{3}$ at constant temperature is the change during the reaction from alkalinity to acidity, which might well be independent of the initial concentration of the ammonium hydroxide.

To determine the effect of a variation of temperature both the chlorine gas and the ammonium hydroxide solution were cooled to about $10^{\circ}$, and the tube was immersed in water at $10^{\circ}$ for about two-thirds its length throughout the experiment. The temperature in the tube during the reaction was undoubtedly higher than $10^{\circ}$ on account of the heat generated in the reaction, but it is to be remembered that there was a similar heating effect in the experiment at $32^{\circ}$. In three consecutive experiments the volume of the nitrogen was $23.2 \%, 23.6 \%$, and $21.6 \%$ the volume of the chlorine $(143.6 \mathrm{cc}$.). These results are markedly lower than those obtained at $32^{\circ}$ but are still much greater than those obtained by Noyes and Lyon with a somewhat smaller proportion of ammonia.

Two experiments were performed in which the ammonium hydroxide solution was added a small portion at a time and a little carbon tetrachloride was introduced into the tube after each portion of the ammonium hydroxide. The solution thus becomes acid after each addition of the ammonium hydroxide and much of the nitrogen trichloride was removed 
by the carbon tetrachloride before the next addition. The volume of the nitrogen formed in the two experiments was $18 \%$ and $20 \%$ the volume of the chlorine used. The large effects produced by this change of the experimental conditions and by the lowering of the temperature furnish evidence unfavorable to the view that Reaction 4 is a stoichiometric reaction, but the evidence is not quite conclusive because our experiments were not conducted exactly in the region where $\mathrm{N}_{2}$ and $\mathrm{NCl}_{3}$ are formed in equimolal quantities.

The great change in the nature of the solution in these experiments and in those of Noyes and Lyon, from initial alkalinity to final acidity, has already been emphasized. As it seemed doubtful if conclusive results could ever be obtained under such conditions it was decided to perform the remainder of the experiments in the presence of various mixtures of phosphates. In a solution which contains equal molal quantities of $\mathrm{Na}_{2} \mathrm{HPO}_{4}$ and $\mathrm{NaH}_{2} \mathrm{PO}_{4}$ the concentration of $\mathrm{H}^{+}$is $2 \times$ IO $^{-7} .1$ The addition of a little strong acid or strong base merely changes the relative amounts of $\mathrm{H}_{2} \mathrm{PO}_{4}^{-}$and $\mathrm{HPO}_{4}^{--}$in the solution, and does not produce a great change in the concentration of hydrogen ion until excess of the acid or base is added. Similarly the concentration of $\mathrm{H}^{+}$in a solution containing $\mathrm{NaH}_{2} \mathrm{PO}_{4}$ and $\mathrm{H}_{3} \mathrm{PO}_{4}$ is approximately o.or $\mathrm{N}$ and, the concentration of $\mathrm{OH}^{-}$in a mixture of $\mathrm{Na}_{2} \mathrm{HPO}_{4}$ and $\mathrm{Na}_{3} \mathrm{PO}_{4}$ is approximately o.or $N$; and moderate amounts of acid or base do not greatly change these concentrations. It is therefore evident that in the presence of phosphates during the reaction between $\mathrm{Cl}_{2}$ and $\mathrm{NH}_{3}$ the concentration of hydrogen ion will change through a much smaller range than in the earlier experiments.

The results of the final series of experiments are summarized below. The quantities of the various solutions added to the ammonium hydroxide solution before the experiment are shown in Cols. 2 to 5 . The reaction towards litmus of the solutions so obtained is shown in Col. 6. The experiments are arranged in the order of decreasing $\mathrm{OH}^{-}$concentration in this solution. The reaction towards litmus of the solutions after the experiment is given in the seventh column, and the volume of the nitrogen rapidly evolved is given in the last column. The experiments were performed at room temperature, about $25^{\circ}$.

These experiments show that a steady and rapid decrease in the volume of nitrogen is produced by a decrease in the concentration of hydroxide ion in the initial solution. The high results in Expts. 6 and 7 are so at variance with the results of all the other experiments that they may be attributed to an experimental error. In the experiment (No. I) in which the initial solution was most highly alkaline the volume of nitrogen is only slightly less than the limiting value, $46 \mathrm{cc}$. (one-third the volume

1 Abbott and Bray, This Jourasi, 3I, 760 (1909). 


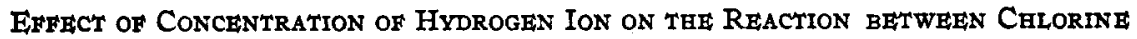
AND AMMONIA.

Chlorine, $0.005625 \mathrm{~mol} ; 138 \mathrm{cc}$. Ammonia, $0.01125 \mathrm{~mol}$.

\begin{tabular}{|c|c|c|c|c|c|c|c|}
\hline \multirow{2}{*}{$\begin{array}{l}\text { Expt. } \\
\text { No. }\end{array}$} & \multicolumn{4}{|c|}{$\begin{array}{l}\text { Amount of substances } \\
\text { added to ammonia solution, in mols. }\end{array}$} & \multicolumn{2}{|c|}{ Reaction of solution to litmus. } & \multirow{2}{*}{$\begin{array}{l}\text { Value } \\
\text { nitrogen. } \\
\text { Ce. }\end{array}$} \\
\hline & NaOH. & $\mathrm{Na}_{8} \mathrm{HPO}_{4}$ & $\mathrm{NaH}_{2} \mathrm{PO}_{4}$ & $\mathrm{H}_{3} \mathrm{PO}_{4}$. & At beginning. & $\overline{\text { At end. }}$ & \\
\hline 1 & 0.010 & o & o & o & Basic & Basic & $45 \cdot 3$ \\
\hline 2 & 0.005 & o & o & o & Basic & Faintly basic & 43.0 \\
\hline 3 & 0 & 0.0112 & o & o & Basic & Faintly basic & 42.8 \\
\hline 4 & o & 0.0084 & 0 & o & Basic & Faintly acid & 42.7 \\
\hline 5 & o & 0.0056 & $\circ$ & 0 & Basic & Faintly acid & 40.5 \\
\hline 6 & 0 & 0.0056 & 0.0028 & 0 & Basic & Acid & $45 \cdot 3$ \\
\hline 7 & 0 & 0.0056 & .0 .0056 & 0 & Basic & Acid & 42.1 \\
\hline 8 & 0 & 0 & 0.0028 & 0 & Basic & Acid & 37.0 \\
\hline 9 & 0 & 0 & 0.0042 & 0 & Basic & Acid & $35 \cdot 7$ \\
\hline 10 & 0 & 0 & 0.0049 & o & Basic & Acid & $34 \cdot 7$ \\
\hline II & 0 & 0 & 0.0084 & o & Basic & Acid & 33.3 \\
\hline 12 & 0 & 0 & 0.0122 & o & Basic & Acid & 31.3 \\
\hline 13 & 0 & $\circ$ & 0.0122 & 0.015 & Basic & Acid & $24 \cdot 7$ \\
\hline 14 & o & 0 & 0.0122 & 0.030 & $\begin{array}{c}\text { Faintly basic } \\
\text { or neutral }\end{array}$ & Acid & 14.7 \\
\hline I5 & o & o & 0.0122 & 0.045 & Faintly acid & Acid & 5.1 \\
\hline
\end{tabular}

of the chlorine). The three final solutions which were basic or faintly basic (Expts. I to 3 ) had the same properties as the final solutions obtained in the experiments with excess ammonium hydroxide, and may have contained some $\mathrm{NH}_{2} \mathrm{Cl}$. It is impossible, however, that this substance was present in appreciable amount in the final solutions in Expts. 8 to 15 , and these may be accepted as corresponding to the Noyes and Lyon experiments. The volume of nitrogen required by their reaction is $23 \mathrm{cc}$; but the rapid change in the volume of the nitrogen, both above and below this value results from such a small variation in the experimental conditions (Expts. I2 to 15 ) that we can safely draw the conclusion that the Noyes and Lyon reaction is not a true stoichiometric reaction.

\section{Possible Relationships between the Reactions Listed in Paragraphs I, 2 and 3 .}

We shall next consider the relationships that may exist between the various reactions listed in the first paragraphs of this article with the object of formulating a theory of the mechanism of these rapid reactions. The reactions in which $\mathrm{NCl}_{3}$ is formed in acid solution and $\mathrm{N}_{2}$ in alkaline solution (Paragraphs $\mathrm{I}$ and 3 ) are reactions of a high order, and therefore probably take place in steps. The only simple bimolecular reaction is the formation of $\mathrm{NH}_{2} \mathrm{Cl}$ (Equation $3 a$ ) discovered by Raschig. The facts that Reaction $3 a+$ Reaction $3^{b}=$ Reaction $2 c$ and that the conditions under which $\mathrm{NH}_{2} \mathrm{Cl}$ decomposes rapidly $(3 b)$ seem to correspond with the conditions under which nitrogen is formed rapidly in Reaction 
$2 c$ indicate that Raschig's experiments can be regarded as the isolation of $\mathrm{NH}_{2} \mathrm{Cl}$ as an intermediate step in the formation of $\mathrm{N}_{2}$ in alkaline solution. The formation of $\mathrm{NH}_{2} \mathrm{Cl}$ is the very rapid primary reaction and its decomposition is the slower follow-reaction. (The latter reaction $(3 b)$, of course, may also take place in steps.) Some further experimental work is necessary on the rate of decomposition of $\mathrm{NH}_{2} \mathrm{Cl}$ under the conditions where $\mathrm{N}_{2}$ is rapidly evolved before we can accept unreservedly this theory of the mechanism of this reaction. However, we do not know of any experimental results which are not in agreement with this theory, and we shall accept it as a working hypothesis. In Reaction $2 a$ between $\mathrm{NH}_{3}$ and $\mathrm{Cl}_{2}$ in the presence of alkali we may assume also that $\mathrm{NH}_{2} \mathrm{Cl}$ is the first step, but it is impossible to decide whether the $\mathrm{NH}_{3}$ reacts directly with $\mathrm{Cl}_{2}$ or with the $\mathrm{ClO}^{-}$formed by the action of $\mathrm{OH}^{-}$on the chlorine.

For the remaining reaction, the formation of $\mathrm{NCl}_{3}$ in acid solution, the simplest theory of the mechanism is that in this case also $\mathrm{NH}_{2} \mathrm{Cl}$ is the primary step. The subsequent rapid formation of $\mathrm{NCl}_{3}$ is easily accounted for when chlorine is present in excess, but the explanation for the rapid and quantitative formation when ammonium ion is present in large excess is much less obvious. One of the simplest explanations is that $\mathrm{NH}_{2} \mathrm{Cl}$ reacts rapidly with hydrogen ion as follows:

$$
{ }_{3} \mathrm{NH}_{2} \mathrm{Cl}+2 \mathrm{H}^{+}=\mathrm{NCl}_{3}+2 \mathrm{NH}_{4}+
$$

This theory has the advantage that it can be tested, and the experiments will be performed as soon as possible. The reaction between $\mathrm{NCl}_{3}$ and very dilute solution of ammonia will also be investigated.

\section{Summary.}

The experimental evidence relating to the various rapid reactions between chlorine and ammonia and to closely allied reactions is discussed.

The reaction discovered by Noyes and Lyon in which nitrogen and nitrogen trichloride are formed in equimolal quantities is studied experimentally and the conclusion is reached that this is not a true stoichiometric reaction.

Raschig's experiments on monochloroamine, $\mathrm{NH}_{2} \mathrm{Cl}$, serve as a basis for the theory that that substance is the primary step in the formation of nitrogen in alkaline solution. The suggestion is made that $\mathrm{NH}_{2} \mathrm{Cl}$ may also be the primary step in the formation of nitrogen chloride in acid solution.

Bergezhy, CaLIFornia.

The authors of the preceding paper are undoubtedly right in their contention that the reaction is not of the ninth order. I am still inclined, however, to think the relation found by Lyons and myself is, in a certain sense, a stoichiometrical one. Raschig's chloroamine was not known 
when our paper was written. It is volatile and if it reacts with ammonium chloride in accordance with the equation

$$
{ }_{3} \mathrm{NH}_{2} \mathrm{Cl}+\mathrm{NH}_{4} \mathrm{Cl}=\mathrm{NCl}_{3}+\mathrm{HCl}+{ }_{3} \mathrm{NH}_{3},
$$

this will account for the fact that we observed, as stated in our paper, a slight absorption of some vapor on shaking the solution containing ammonium chloride with the residual nitrogen. If we add the three equations

(I) $6 \mathrm{NH}_{3}+6 \mathrm{Cl}_{2}=6 \mathrm{NH}_{2} \mathrm{Cl}+6 \mathrm{HCl}$

(2) ${ }_{3} \mathrm{NH}_{2} \mathrm{Cl}=\mathrm{N}_{2}+\mathrm{NH}_{4} \mathrm{Cl}+2 \mathrm{HCl}$

(3) ${ }_{3} \mathrm{NH}_{2} \mathrm{Cl}+\mathrm{NH}_{4} \mathrm{Cl}={ }_{3} \mathrm{NH}_{3}+\mathrm{NCl}_{3}+\mathrm{HCl}$

(4) $3 \mathrm{NH}_{3}+6 \mathrm{Cl}_{2}=\mathrm{N}_{2}+\mathrm{NCl}_{3}+{ }_{9} \mathrm{HCl}$

the sum is the equation given by Lyon and myself. The use of two mols of ammonia for one of chlorine seems to cause the reaction to balance almost exactly in accordance with the final equation. This seems to be connected with the fact that Reaction 2 gives the one mol of ammonium chloride required by Reaction 3. However, Bray and Dowell are right in considering that such a result is due to a balance between different reactions, either of which may become more prominent under slightly changed conditions.

Reaction $I$ is almost surely the primary reaction. This is evidently very rapid and may be followed almost quantitatively by Reaction 3 in a cold, faintly acid solution, as shown by the last experiment in the preceding paper p. 9ri. Reaction 3 doubtless occurs in stages.

$$
\begin{aligned}
\mathrm{NH}_{2} \mathrm{Cl}+\mathrm{NH}_{4} \mathrm{Cl} & =\mathrm{NH}_{3}+\mathrm{NH}_{3} \mathrm{Cl}_{2} \\
\mathrm{NH}_{2} \mathrm{Cl}+\mathrm{NH}_{3} \mathrm{Cl}_{2} & =\mathrm{NH}_{2} \mathrm{Cl}_{3}+\mathrm{NH}_{3} \text {, etc. }
\end{aligned}
$$

Reaction 2 also probably occurs in stages. Raschig ${ }^{1}$.has shown that hydrazine may be formed in considerable amount from chloroamine, $\mathrm{NH}_{2} \mathrm{Cl}$, and ammonia. This involves a change of a positive chlorine atom to a negative one and of a negative nitrogen atom to a positive.

$$
\begin{gathered}
-+\mathrm{H} \\
\mathrm{N}-+\mathrm{H} \\
-+\mathrm{Cl}
\end{gathered}=\mathrm{N}-\mathrm{H}+\mathrm{H}+-\mathrm{Cl} .
$$

The unsaturated $\mathrm{NH}$ group would then add ammonia $\left(\mathrm{NH}_{2} \mathrm{H}\right)$ as is customary for unsaturated substances in general, giving hydrazine, $\mathrm{H}_{2} \mathrm{~N}+-\mathrm{NH}_{2}$. The hydrazine might either react with monochloroamine giving the compounds $\mathrm{NH}_{2}-\mathrm{NHCl}$ and $\mathrm{NH}_{2}-\mathrm{NCl}_{2}$, which would rearrange to nitrogen and hydrochloric acid or the hypochlorous acid formed by the hydrolysis of $\mathrm{NH}_{2} \mathrm{Cl}$ or $\mathrm{NCl}_{3}$ might oxidize the hydrazine to nitrogen and water.

URBANA, ILI.

W. A. NOYES.

\footnotetext{
i Loc. cit.
} 